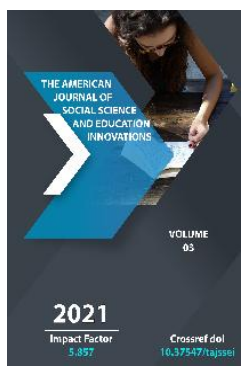

\title{
The Role Of Actual Units Of Division In The Compositional- Syntactic Structure Of Poetic Speech
}

\author{
Mukhammadtokhir Tojimamatovich Abdupattoev \\ Candidate Of Philology, Associate Professor, Fergana State University, Fergana, Uzbekistan
}

Journal Website:

http://theamericanjour

nals.com/index.php/taj

ssei

Copyright: Original content from this work may be used under the terms of the creative commons attributes 4.0 licence.

\section{ABSTRACT}

The article presents theoretical views on the compositional-syntactic structure of poetic speech, which is one of the problematic issues in the field of poetic syntax and the study of its actual division. Within the framework of the Uzbek poetic syntax, the importance of studying the issue of actual division as a separate category in the study of Uzbek poetic speech based on the experience of world linguistics.

\section{KEYWORDS}

Linguopoetic, syntax, poetic syntax, poetic speech, actualization, subject-material relations, expressiveness, communication, predicate, subject.

\section{INTRODUCTION}

Any poetic speech means a certain dialogue between the listener and its author, in which the listener acts only as the addressee. With a communicative approach to speech analysis, the position of the author of the speech as an addressee is of great importance in the compositional-syntactic structure of speech. It should be noted that poetic speech has many ways and means of expression, because it is a

complex and multifaceted syntactic structure. Accordingly, in the compositional-syntactic formation of poetic speech content, various methods and means are used. The question of the role of actual units of division in the 
compositional-syntactic structure of poetic speech is of great importance.

\section{MAIN PART}

Another view of the semantic-syntactic relations between the parts of poetic speech is manifested in the form of actual division and plays an important role in the compositionalsyntactic structure of speech, since in the syntactic whole, the relation of the subject and the rheme constitutes the problem of the actual division of speech. The actual division was originally applied to speech in linguistics. Czech scientist V. Matezius, who founded the theory of the actual division of speech as a special linguistic direction [1].

According to him, the sentence consists of two parts: the starting point of thought - the part (theme) known from the situation, easily understood from the previous speech situation, and the communicative center - the part (rheme), which is the main information in the sentence. I.P. Raspopov is a scientist dealing with the problem of actual division in Russian linguistics [2].

The problem of the actual division into syntactic units has attracted the attention of Turkologists since the 70s of the last centure. It should be noted the articles and main studies of R.S.Amirova, F.M.Agaeva, K.N.Valiev[3].

Coverage of the problem of the actual division of speech in Uzbek linguistics dates back to the 70 s of the last century, and as a result, A. Hayitmetov's monographic research appeared [4]. In Uzbek linguistics, the units of division proper - the relationship between the theme and the rheme - study mainly in the context of simple sentences, and the study of these issues using the example of complex sentences and complex speech units remains relevant.

It is well known, that in syntactic construction as units of actual division, most scientists determine the basis of the expression of a sentence - the theme and the core of the expression - rheme. The author of the speech and the listener or reader are part of the communication mechanism. A subject is a new message, information that is transmitted to the rest of the addressee, often if the subject is known to both of them in advance. Apparently, it is also studied in the semantic aspect as a syntactic category and serves as the basis for the compositional-syntactic formation of poetic speech.

A person often interacts not with words taken separately, but with the help of statements in which the content is interconnected, extracted from each other and communicates with each other in a certain way. Consequently, speech comes first in terms of performing the communicative function. Consequently, the compositional-syntactic structure of speech is associated with the problem of actual division. There is also a thematic division in a speech: the theme (theme), the topic of the speech (what is at stake), and the message (rheme) is the coverage of the topic, what it consists of.

In large poetic works, the theme is revealed throughout the entire work. In small volumes (poems, quartets), a new message on the topic (rheme) is announced in the same small volume.

The world is like a market,

The world is like a market.

I have not seen any of these two, 
Who badly called theirs things. (A.Oripov)

In the compositional and syntactic structure of this quartet, the theme is clarified first of all the world, and the rest of the lines appear in the rheme function, that is, new author's messages about the world - experiences, feelings - are expressed. As you can see, in the compositional-syntactic structure of poetic speech, the theme-rheme relation, showing the semantic connection between parts (lines), played an important role in ensuring the integrity of poetic speech, the consistent development and conclusion of thought. ... In addition, to ensure a strong semantic and syntactic connection between sentences (lines) and to enhance the emotional impact, a syntactic figure was used - repetition (multiple use of a combination similar to the market one), synonyms (market, product)....

It is well known that every sentence is based on judgment. In other words, judgment is expressed through judgment. As the linguist A. Nurmonov noted, judgment and speech form a dialectical unity. Typically, each sentence contains three main elements: subject, predicate and glue $[5,72]$. Therefore, a sentence semantically consists of a subject, a predicate, and a linking relation. Since this attitude exists in any form of speech, it also forms the basis of sentences equivalent to the topic of speech. When we semantically examine sentences that are equivalent to the theme of poetic speech, we see that the existing subject is important in relation to the subject-rem of speech.

\section{RESULTS AND DISCUSSIONS}

It is well known that under the term subject different concepts are combined, that is, the predicate is interpreted as the owner of different symbols. Linguists note that the subject of speech grammatically masters or is expressed through an addition. The topic of a sentence corresponding to the topic of poetic speech is interpreted and expanded by a series of sentences equivalent to rheme. In this case, no matter what concept the subject of the subject expresses, the words expressing rhyme continue, that is, expand the ideas related to this subject. Based on the nature of the collected and analyzed examples, we considered it necessary to highlight the following types of subject meanings.

1. Comment related to the topic of the action:

Occasionally riding on a horse of anger,

Terrible crying madman Kokand's wind

Your eyes are narrowed, your ears are pierced,

You cannot separate the sky from the ground. (Iqbol Mirzo)

From the quoted passage of poetic speech, it is clear that the subject of speech (subject of action), which is equivalent to the subject, is explained by the "wind", and its action is rheme. The influence of an object on existence is widely and comprehensively revealed in rhyme. This gives the reader the opportunity to complete a specific idea. Known and new - in the above-mentioned manifestation of the theme-rheme relationship, mainly the object and its action play an important role

2. Comment on the topic of the case:

The blue sea buried all

Gust slowly touches to my face,

Sight buries in heart of the day 
From a far I see cotton picking girls.

My heart is full of enjoy and sing-songs;

Dream and desire to rise like the sky.

The white flowers are already in full bloom

Big crowd likes cloud is fulling life

(Usmon Nosir)

The theme of this poetic discourse is the poet's momentary experiences, which, as you can see, constitute the subject of the situation (static subject) in accordance with the subject of the subject. Rheme begins with the first sentence in the speech itself. The main emphasis is on the state of the subject in predicative units, which constitute the rhyme used to provide, complete and interpret a complete description of the subject's situation.

The state of the object is explained by such verb forms as "buried", "touches", "picking", "full", "rise", "full". It is known that the verb forms denoting the passive action of the subject are characteristic of the figurativespeech type, in which the situation prevails over the action. A similar situation can be seen in the passage above.

3. A comment related to the object on which the sign stands. In cases where the subject in the sentence expressing the topic is of a qualitative nature, the main emphasis in the topic is placed on the nature of the subject. The same law is preserved in the sentences that make up rheme. That is the subject sign is expanded by the interpretation:

Woman's hands are rough, Woman's dress is rough.
Husband beats her every day,

Bruises on her face every day. (X. Davron)

Even in the cited poetic discourse, as noted above, rheme serves as an explanation, enumerating the distinguishing features of the qualitative subject in the subject. At the same time, words characteristic of the adjective phrase, as well as adjectives and adverbial forms of the verb, are more often used (since the main emphasis is on the interpretation of the subject sign). Our example above uses a feminine theme and its characteristic features are interpreted rhymingly.

4. Annotation related to a quantitative object. In poetic speech, in which theme is a quantitative defining subject in the subject and which is interpreted in theme, the subject indicates the quantitative attribute of the subject. However, in rheme the same amount is explained and justified. To complete it, evidence is provided:

There are many thousand year old ruins in the world,

Memory of the wars, memory of the floods

The graves are stacked high

In fact, they are also large ruins. (A.Oripov)

As you can see from this example, the number of subjects is justified and explained (plural) rheme. In rhyme, the use of quantitative (topdown) tokens also provides a certain semantic link, as well as a special integrity of the topicrheme relationship.

5. Comment related to the subject of ownership. In poetic discourse, in which the subject in the subject has a positive character, it is implied that the subject has 
something. In the rheme however, explains this with additional information.

You are my sky, my hot heart,

Not my surroundings, my sun,

My confidence, my joy, my consolation again

My missing, my regreting, my hurting.

You are my heart, a poem in my heart

I dreamed of finishing without a common book.

My love and life, the rest of my life

My happy, my pleasure and my pain. (Iqbol Mirzo)

From the above poetic speech, it is clear that the subject of the theme - "my" - "my sky, my hot heart, my sun, my faith, my joy, my consolation, my aspiration, my regret, my suffering ..." is explained in rheme. The reasons for possessing these characteristics are specified. The continuation of the use of possessive suffixes in rheme, denoting and indicating property, serves to explain, complement, while providing a connection between the theme-rheme, as well as the general characteristics of the subject of ownership in the subject.

6. Commentary related to the topic of accessibility:

In the theme of such speech, the existence of an object from the point of view of the present is expressed by a statement and it is asserted that the subject of poetic speech is about this subject. In the rheme the characteristics of the subject of existence are referred to through interpretation.
Uzbeks have as long as been hospitable

They say the guest is important than your father.

Putting all the things what have to a daytime guest

And after eaten dried apricots for a long time. (Sh. Rahmon)

In the given example, the subject expresses the existence of the Uzbek people and through rheme this existence reflects the interpretation of the characteristics of the subject, additional information about his specific impact on the object - the outside world.

In poetic speech, this type of meaning of the object is manifested through

7. Commentary related to the subject speech situation.

The context, situation (situation). This topic constituting the theme, requires an explanation of the situation. The situational topic is given in the thematic part of the poetic speech and its essence is revealed in the theme.

The blue sky was covered with clouds,

The old man's face was covered with anger,

A cloud came and threw three or four drops

To the old man's head

The old man was full of anger and moan,

His pale eyes were burning,

He was on fire, in a nervous tone,

His words were on his lips ... ( Uygun) 
In the rheme of this poetic passage, a situation is given where the rhetoric is explained in rhyme: "The blue sky is clouded, the face of the old man is slowly overflowing with rage." Thus, the content of the topic arises in connection with the general contextual situation (situation). From this point of view on the subject-object relationship in poetic speech, this type of meaning of the subject in the subject plays an important function. Because figurative and affective lexemes related to the subject require a general thematic (contextual) situation in this context. This function is performed by the rheme type of comment.

\section{Note referring to the compared item.}

When this view of the subject is included in the theme of speech, it is compared with something - another subject, person, etc., Comparison expressed in the theme is further expanded and explained in rheme.

You're good

I am bad,

If you leave, I am safe.

The killer life that made me

Useless, helpless who created you. (E. Vohidov)

Apparently, as a comparable topic in the above poetic speech, "you" are involved in this theme. The analogy expressed in the theme continues in the rest of the speech, i.e. the author relies on the characters of two faces (you and the lyrical protagonist) by the method of opposition. It is characterized by the presence of lexical elements such as words and relative, while the subject is comparable in sentences expressing both the theme and rheme in speech with a comparable subject. In such poetic speeches, since the signs of a person or an object are compared (a sign in the broadest sense), words belonging to the category of adjectives are more often used in sentences that make up speech, and thus a goal is set. In the example above, the antonyms of good, evil, helplessness, useness, day and night, life and death were used to reinforce the comparison.

9. Commentary related to the theme of the gang.

The subject of a gang in the SSB topic refers to his belonging to a certain group, gang or class, profession. In this case, an important role is played by the predicate related to the subject in the theme. As A. Nurmanov points out, in this case the predicate is represented by a noun denoting the type (class) of the subject[5,74].

In the rheme of poetic speech, specific common features of the type or class to which the subject belongs are expressed in the form of comments:

Do not be surprised by the poets

The poet's people are diverse.

Sometimes proud, sometimes diltang,

Sometimes sad, sometimes gloomy.

(E. Vohidov)

From the given example, we can conclude that the characteristic features of the type to which the qualifying subject belongs in the subject of poetic speech have been expanded and explained. The first sentence of the above passage implies that the subject is poets, and the revised one gives general characteristics of the owners of this profession (poetry) and also explains that there are other similar signs. 
10. A comment related to a functioning object.

In this case, the main function (task) of the subject is reflected in the theme of poetic speech. For example: harvester, harvester, thresher. The teacher teaches students, shares knowledge. How a hairdresser gets his hair. However, in the rheme explains this feature;

A real actor is an artist whose heart is pounding.

Almost sees the day.

There are people who cry with one eye

One eye smiles.

There are people like that, oh my father,

Instantly changing font, ink.

But then, at that second

Standing leg on the breast of the mother. (A.Oripov)

The above points are also confirmed by the quoted passage from the poetic speech. The functional subject in the subject of speech is assigned the main function (function) of the characters. In the rheme some aspects of this function are expanded, and the characters of the "characters" in life are shown figuratively.

The above points are also confirmed by the quoted passage from the poetic speech. The functional subject in the subject of speech is assigned the main function (function) of the characters. In the rheme some aspects of this function are expanded, and the characters of the "characters" in life are shown figuratively. Thus, we can observe that the presence of a certain emotional coloring, a significant effect is provided in poetic speech.

11. Commentary related to the perceived subject.

When this type of subject matter of poetic speech is interpreted in rheme, the theme in the subject basically refers to the perceived person or certain creatures. Perception, cognition, perception are shown as the main subjective attribute of an object. The rheme of poetic speech explains the result of the same perception, knowledge, perception (of what they know):

I know them, they will be pure,

His heart will be as pure as a baby

We live without realizing

Next to us

These tall people will be humiliated. (Sh. Rahmon)

In this example, it is also observed that the subject of the theme - knowledge and understanding of the lyrical protagonist - is explained in rheme with the help of emotional means and provides compositionally and syntactically correct construction of poetic speech.

12. Evaluation or comment related to the subject in emotional relationships: in such cases, the subject of poetic speech expresses the value, attitude, influence and inner feelings of the subject to another object, subject or person. M: I love my brother. As if he loves everyone. However, at rheme, this relationship is gradually evolving, and their reasons are explained and explained. 
Every time I did wrong, I did wrong.

I didn't look at you, I hurt my eyes.

I didn't go, I didn't go, I didn't go

I did not take compensation from the land, I was offended.

Only the oppressed know the taste of oppression

I am sorry when I see happy people. (Iqbol Mirzo)

The above points can be continued in the quoted passage. Evaluation on the theme of poetic speech or attitude and evaluation of the subject in an emotional relationship is explained on the basis of rhyme.

13. Commentary related to the subject of kinship or social relations. The theme in the theme of poetic speech is used in this case together with the predicate horses, which express the meanings of kinship, social connection. The rheme reveals the symbols associated with the person or object represented by the predicate, and provides additional information about him:

The synonym of the word "heart" is "sister".

Sister!

My heart warms when I tell you.

The heart is beating weakly

My pure, sister,

Lovely, sister! (Iqbol Mirzo)

In the above example, the subject of kinship in the theme (the theme of poetic speech) is the sister, and details and events related to the sister in the rheme are described.

14. Commentary related to the subject of the seat.

The plot of a place is also common in poetic speech, because logically an event or an image is associated with a certain place:

The field is like an abandoned yard,

The trees are bathing like a young woman,

The bird's dream is like a creature,

The soul is immersed in emotions.

(E. Shukur)

In this example, the field, or rather the field, which was built as an ownerless courtyard, acted as a locative subject, and poetic speech played an important role in the compositional and syntactic construction of the theme. In the rheme describes the image of the field and the author's feelings and experiences associated with the field. Consequently, the indicated system of meanings of an object is observed in the subject of poetic speech. Rheme on the other hand, is realized mainly through the interpretation of the meanings of the object in the object. From the above, we can conclude that in poetic speech, as in the case of speech, there is a theme-rheme relationship - an actual division.

\section{CONCLUSION}

Rhema, on the other hand, consists of sentences (lines) that form the following parts of poetic speech. The relationship between them serves as an important tool in the formation of the compositional and syntactic structure of poetic speech. This, in turn, ensures the logical coherence of poetic speech and the formation of poetic speech as 
a syntactically and semantically integral device.

\section{REFERENCES}

1. Mattius V. About the so-called actual division of the proposal. "Praisky linguistic circle" M., 1967.

2. Raspov I.P. Actual members and communicative syntactic types of declarative sentences in Russian. ADD. M., 1964.

3. Amirov R.S. Stosob of an actual member in the Kazakh language. "Soviet Turkology". 1970. No. 6, Agaeva F.M. The syntax of Azerbaijani colloquial speech. ADD. M., 1979. Valiev K.N. Semantic (actual) purpose in the Turkic languages. Sh AllUnion Turk. Conf (abstracts and reports) "Linguistics", Tashkent, 1980.

4. Khaitmetov A. Actual separation of speech and positional issues in the Uzbek language. Tashkent. Fan, 1984.

5. Nurmonov A.N. Syntactic theories of speech (special course for students). Tashkent. 1988 p. 72.

6. Abdupattoev, M.(2021). COMPOSITIONAL STRUCTURE OF MICROMATES. Конференции, 1(2). https://doi.org/10.47100/.v1i2.153.

7. Abdupattoev M. T. Unusual Connections As Forming Literary Text //The American Journal of Social Science and Education Innovations. - 2021. - T. 3. - №. 02. - C. 177-182. 